\title{
Dissecting the offshore wind and mariculture multi-use discourse: a new approach using targeted SWOT analysis
}

\author{
Maximilian Felix Schupp ${ }^{1,2}$ (D) $\cdot$ Gesche Krause $^{1}$ (D) $\cdot$ Vincent Onyango $^{2}$ (D) $\cdot$ Bela H. Buck $^{1,3}$ (D)
}

Received: 17 April 2020 / Accepted: 18 February 2021 / Published online: 10 March 2021

(C) The Author(s) 2021

\begin{abstract}
Coastal seas around the world are under increasing anthropogenic pressures due to the rapid expansion of maritime industry and coastal urbanisation. Multi-use (MU) of ocean space, meaning the use of the same space by multiple resource users, has emerged as one strategy to address spatial conflicts resulting from an increasing use density. The proposed multi-use of offshore wind farms (OWF) and mariculture (MAQ) is one of the most-researched examples of such a potentially symbiotic relationship. Two decades of public and academic discourse have produced an abundance of research regarding various facets of this particular combination. Nevertheless, the latest research projects of the EUs Horizon 2020 Research and Innovation Programme have identified a number of persistent barriers to continued multi-use development. The past and current public discourse has created a situation where technological readiness has outpaced societal readiness and the discussion is often complicated by the diversity of backgrounds and perceptions of the participants of this discourse. This study aims to dissect the common discourse on OWF and mariculture multi-use by utilising a targeted SWOT analysis approach based on stakeholder knowledge. This approach reveals two distinct narratives based around societal and economic considerations respectively. From this, we derive a set of tailor-made recommendations for policy makers and regulators as well as funding agencies, businesses and researchers.
\end{abstract}

Keywords Mariculture $\cdot$ Multi-use $\cdot$ Offshore wind energy $\cdot$ Co-location $\cdot$ SWOT analysis, stakeholder perceptions

\section{Introduction}

The sustainable and efficient use of our oceans is paramount to addressing the twenty-first century's challenges of climate change, food security, poverty, hunger and renewable energy as well as nature conservation as depicted by the United Nations Sustainable Development Goals (UN. 2015; ICSU 2017). Towards this end, multi-use of ocean space has emerged as a new spatial use concept to further the development of future ocean industries such as mariculture, marine

Maximilian Felix Schupp

maximilian.felix.schupp@awi.de

$1 \quad$ Alfred Wegener Institute, Helmholtz Centre for Polar and Marine Research, Bremerhaven, Germany

2 School of Social Sciences, University of Dundee, Dundee, Scotland, UK

3 University of Applied Sciences Bremerhaven, Bremerhaven, Germany renewables and eco-tourism (Buck et al. 2008; Bocci et al. 2019; Schupp et al. 2019).

Such multi-use concepts represent a step in the transformation of conventional spatial-use concepts towards a more efficient and potentially both socially and ecologically more sustainable use of our oceans (Schupp et al. 2019; van den Burg et al. 2020).

One often proposed multi-use scenario is the combination of marine aquaculture, or mariculture, and offshore wind farms in multiple sea basins around the world (Buck and Langan 2017; Jansen et al. 2016). Such a combination of sectors could potentially increase the production of renewable energy by making attaining and maintaining of a societal license to operate (SLO) easier for wind farms operators, while simultaneously providing additional jobs and food for human consumption or highvalue downstream products and extracts from culture organisms such as macroalgae, shellfish and finfish.

This study employs a case study approach using narrative scenario planning following Rasmussen (2008) to explore the status quo of the mariculture and offshore wind multi-use combination in Germany's exclusive economic zone (EEZ) of the North Sea. 
To date, the combination has been explored at both the national and international levels (Buck et al. 2017; Buck and Langan 2017) using a variety of approaches. Approaches included spatial planning exercises identifying promising multiuse areas (Stelzenmüller et al. 2017), stakeholder engagement focussed on identifying perceptions and opinions (MichlerCieluch and Kodeih 2008; Michler-Cieluch et al. 2009a; Michler-Cieluch and Krause 2008) or meta-analyses of available research data, mostly focussing on technological and economic feasibility through a research and technology lens and viability (van den Burg et al. 2019). The latest investigations, however, showed a number of barriers, such as shortcomings in legislation, sectoral thinking or high administrative burdens still hindering the further development of this combination of uses (Onyango et al. 2020; Schultz-Zehden et al. 2018).

In an effort to advance and reframe the common discourse on multi-use development, the results of an extensive review of relevant past projects in the case study area are complemented by the common perceptions of a set of four key stakeholders. These perceptions were gathered through in-depth semi-structured qualitative interviews following the approach of Helfferich (2011). The results are then analysed and discussed using a two-dimensional, stakeholder-informed SWOT (Strength, Weakness, Opportunities, and Threats) analysis focussing on societal as well as industry dimensions.

This approach updates and builds on the past work reviewed in Buck et al. (2017) by reframing the current discourse using the SWOT methodology and incorporating stakeholder perceptions into the common narrative created by past research projects. It focusses on those perceptions of stakeholders from the involved industries, regulators and academia. Dissecting the SWOT analysis into both industry and society focussed sub-analyses creates an accounting of both internal and external factors relevant to the future development of the combination and helps to separate common narratives which are otherwise often conflated. This bi-focal analysis aims to provide a clearer picture of currently known factors for policy makers, regulators and academia, as well as funding agencies and businesses looking to invest in an emerging market. Based on this analysis, we present a targeted set of recommendations to support future development and create scope for sustainable growth and innovation.

\section{Materials and methods}

This analysis follows the methodological framework depicted in Fig. 1 and is loosely adapted from the MUSES (Multi-Use in European Seas) project methodology presented in Bocci et al. (2019). While the MUSES project employed a DABI (drivers, added value, barriers, impacts) approach to analyse potentials, this analysis focusses on the SWOT methodology.

\section{SWOT analysis}

The SWOT analysis has long been used as an instrument for strategic and policy planning in economic settings (Stavroulakis and Papadimitriou 2015) but has recently also been applied as a strategic planning aid in other sectors (Goffetti et al. 2018). It is a strategic analysis tool focussed on achieving change and can be utilised to help understand complex predefined concepts while focussing on identifying changes and strategies which improve the concept. It allows for a better structured qualitative analysis of concepts over the traditional discourse analysis and promotes a multidimensional analysis compared to the more economically focussed cost-benefit analysis (Fertel et al. 2013). Recent more novel applications include the analysis of energy policy (Fertel et al. 2013) and the marine renewables sector in Italy (Goffetti et al. 2018), as well as the rigs-to-reefs decommissioning strategy for offshore structures (Smyth et al. 2015), with a focus on identifying avenues for possible sustainable change.

In the context of multi-use of ocean space, this approach was previously only deployed to analyse compartmentalized aspects of such multi-use combinations, e.g. the integration of operation and management (O\&M) activities by MichlerCieluch et al. (2009b) or Wever et al. (2015). However, the advantage and strength of the approach of the SWOT methodology rest on systematically assessing and contrasting all internal and external factors relevant to strategic decision making. This is the first study to apply this approach to the OWF and mariculture concept as a whole. This qualitative assessment and presentation allows decision makers to grasp strategic situations and assess actions in order to capitalize on strengths, address weaknesses, realize opportunities and avoid or minimize threats (Fertel et al. 2013). Internal and external factors have to be separated and contrasted to distil the inherent and current strengths and weaknesses that characterize a strategic situation. Whilst external factors are those potential opportunities and threats which might directly or indirectly affect the situation in the future, internal factors are the strengths and weaknesses inherent to the situation (Dyson 2004).

\section{Desk-based research}

The complete SWOT factor catalogue was based on a review of available peer-reviewed sources as well available grey literature. Grey literature included national marine plans, sectoral roadmaps and reports, as well as project reports and other deliverables. Using expert consultation and a variation of the snowball sampling principle (Biernacki and Waldorf 1981), 27 past international and national multi-use projects were identified world-wide. Ten past projects were identified within the case study area. The main selection criteria for inclusion 
Fig. 1 Process model of a twostage iterative SWOT framework. (1) Reviewing and collating information to create first SWOT catalogue. (2) Discussion with key stakeholders during narrative qualitative interviews to amend catalogue based on current industry knowledge. (3) Splitting of SWOT analysis into society and industry focussed factors. (4) Postulating recommendations based on information collected during steps 1 and 2. (5) Fine tune recommendations with input from the same group of key stakeholders. Adapted and modified from Bocci et al. (2019)

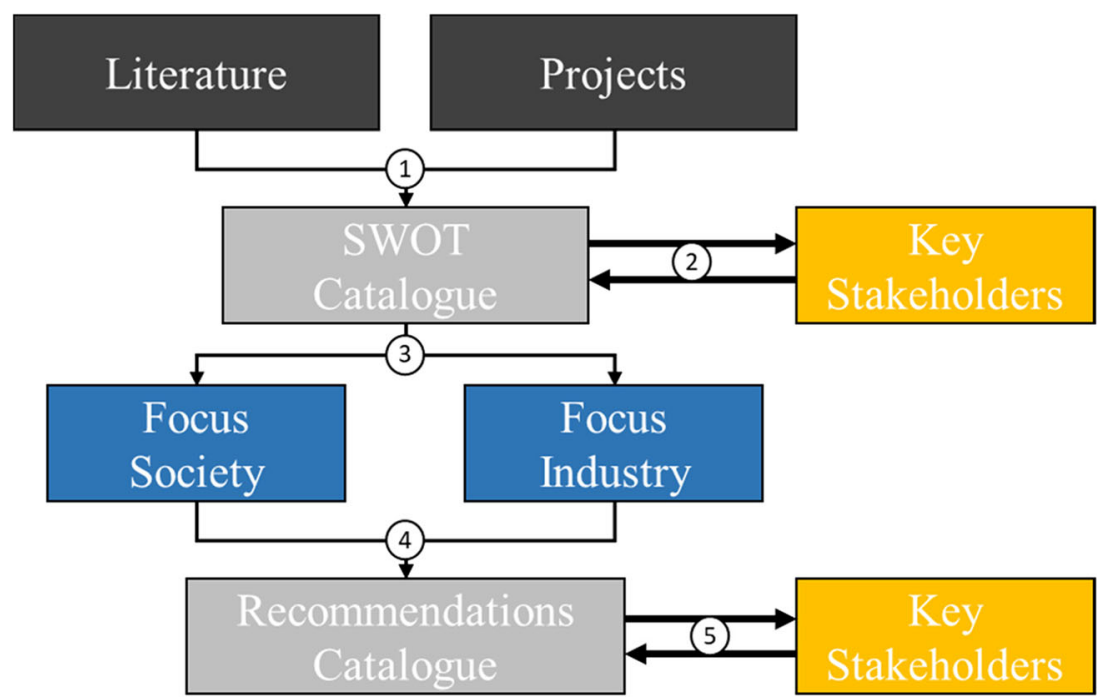

were the availability of research results as either peerreviewed or grey literature, a focus on the OWF and mariculture multi-use combination and an experimental component or stakeholder engagement. Pure desktop studies were excluded. The ten identified relevant previous research projects in the study area are listed in Table 1. All identified past projects practised stakeholder engagement. Methods ranged from the integration of stakeholders into the research process during varying stages of the projects, to qualitative interviews and inclusion of stakeholders in project workshops in order to validate and disseminate research results.

The review focusses solely on SWOT factors that arise out of the combination of the uses and disregards single sector challenges, such as supply chain issues or work force availability, which are often already addressed in sectoral strategies. The distinction between sectoral and multi-use challenges was made based on whether a specific challenge would persist in a single-use scenario or whether it would only become relevant in a multi-use setting. This review resulted in a catalogue of factors for a complete SWOT analysis (Fig. 1, step 1).

\section{Stakeholder identification and selection}

A stakeholder mapping of all relevant stakeholders within industry, regulatory bodies, the wider society and academia was conducted with the goal of identifying key knowledge holders within the respective communities. Using deskbased research, supplemented with expert consultations and the snowball method, 96 stakeholders were identified from the offshore wind energy, mariculture and fisheries sectors, regulatory agencies and NGOs, as well as associated industries.

The factor catalogue, created through the review of past projects and available literature, was discussed with a selection of four key stakeholders during in-depth semi-structured qualitative interviews. These four stakeholders represented the involved sectors, offshore wind energy and mariculture, and academia, as well as the key regulatory body for this development.

Key stakeholders were defined as those who have an overarching knowledge of their sector and its challenges and are situated in leading positions in their respective fields. Representatives of industry wide cluster associations were chosen to represent the mariculture and OWF sectors in order to gain a broader perspective of sectoral view points over company and project-specific views. The key regulatory stakeholder was chosen from Germany's federal authority in charge of permitting single and multi-uses in the EEZ. The key stakeholder from academia was chosen from researchers who had previously been involved in multi-use research projects in Germany's national context but were not involved with the MUSES projects or this analysis. All stakeholders were chosen based on their position in their organisation and therefore access to knowledge, as well as their prior participation within the academic and public discourse on multi-use in Germany and abroad.

\section{Interview methodology}

A series of four semi-structured qualitative expert interviews were conducted, according to Helfferich (2011) and Tansey (2009), in order to record the subjective opinions and perceptions of key knowledge holders in the field. All interviewees were provided with a consent form about the purpose of the interview, the study, detailing the collected data and its intended purpose before the commencement of interviews (Fig. 1, step 2). All participants agreed to the publishing of the non-identifiable data and expressed views. The interviews were not recorded and transcribed, as participation largely depended on maintaining the trust and privacy of the 


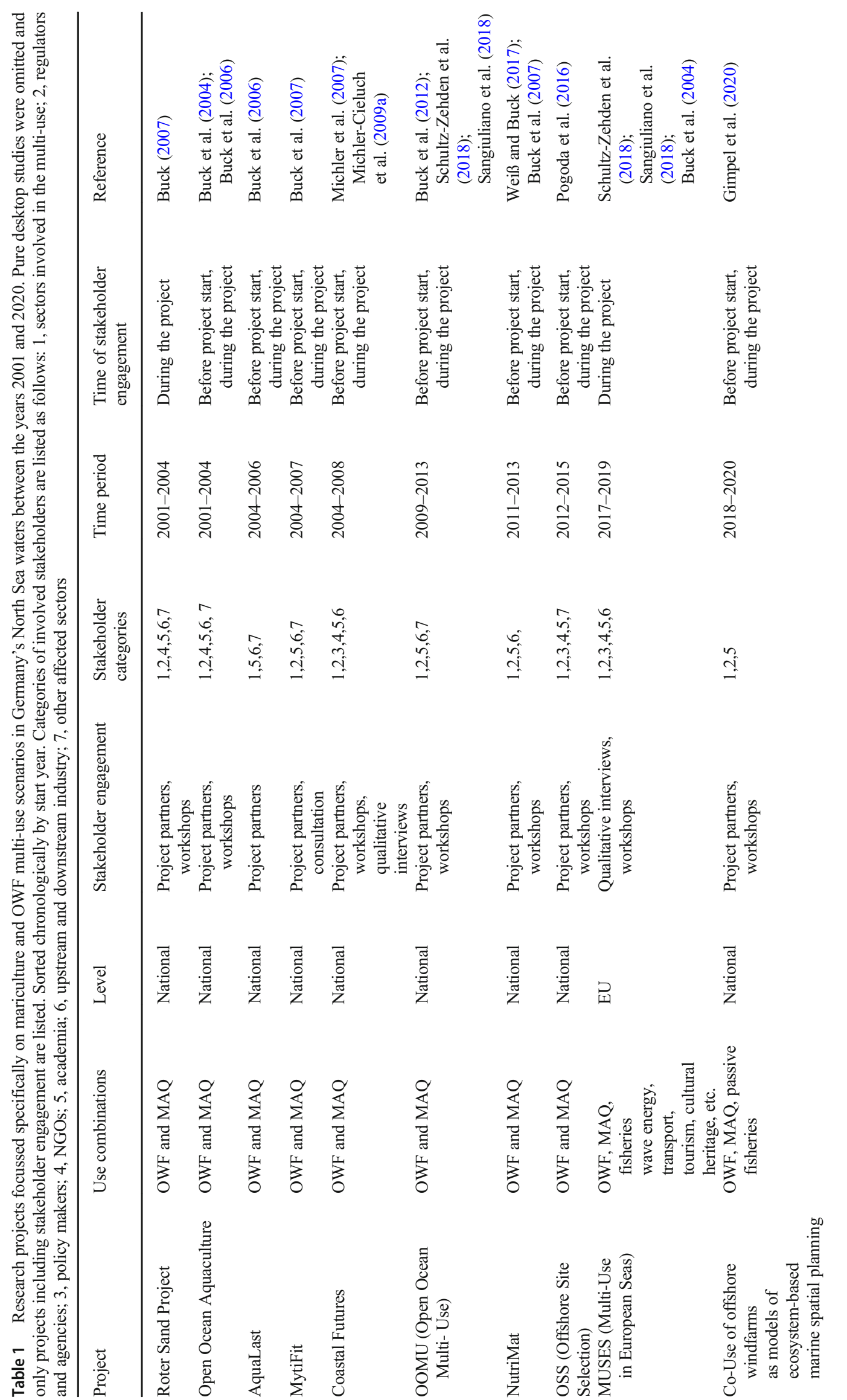


participants. Viewpoints and discussion were instead noted during the interviews and notes immediately validated by the interviewee. Interviews were conducted in-person and lasted approximately $2 \mathrm{~h}$ each. The semi-structured qualitative interviews consisted of two parts. First, a common structured question protocol (Supplementary Material 1) was followed, which served to centre the interviewees on the topic of multiuse within the case study area. During the second part, the complete SWOT factor catalogue was presented and each factor discussed and amended where necessary. All new factors which arose during later interviews were communicated and discussed with previous interviewees after the interview phase was concluded. Using this approach, all factors presented here could be discussed with all interviewees, allowing for a more complete set of factors.

The catalogue of recommendations derived from the SWOT approach was sent to each interviewee for review and revision (Fig. 1, step 5) before arriving at the final version presented in Table 5.

\section{Dissecting the SWOT analysis}

In order to dissect the conflated and ongoing discourse and separate the underlying themes, the complete catalogue of factors was further categorised into two sub-analyses with a specific focus on perspectives focussing on society and industry (Fig. 1, step 3). Societal factors are defined by the authors as those which are deemed primarily relevant to the wider civil society as a whole, meaning relevant to the provision and maintenance of society and affecting all members of it. This includes factors pertaining to the sustainable growth of the wider economy and regional economic development. Factors which are primarily relevant to the involved businesses or sectors are classified as industry factors. In accordance with the United Nations' agenda for sustainable development (UN. 2015) and the German government's agenda for sustainable development (BMZ 2017), it is assumed that all factors relevant to the sustainable use of the environment are relevant to society and are therefore included in the society-centric SWOT analysis. It is understood that both industry and society are part of the same multi-facetted system and factors are assigned according to their primary relevance only. The resulting two sub-analyses represent a split of the previously conflated discourse and form a basis for future elaboration with both societal and industry stakeholders.

These two focal points of the analysis, the societal and industry focus, aimed to de-construct the common narratives dominating the public and academic discourse and remove a level of bias from each sub-analysis. This bias stems from conflating the goals of various different groups in one discussion, when there really is a need for separate discussion. Based on the two analyses, a common catalogue of recommendations was prepared in conjunction with key stakeholders.
Specific recommendations are targeted at actors from the research community, policy makers, regulators and funding organisations as well as private sector actors and investors.

\section{Limits of the methodology}

Qualitative interviews can give context to the current state of MU research; however, the approach poses inherent challenges which need to be considered while analysing the results. Though identifying and including key stakeholders serves to distil as many varying viewpoints into one qualitative analysis as possible, it is however important to consider the limitations of any qualitative approach trying to analyse and depict the viewpoint of a society that is comprised of such a large variety of independent actors (Helfferich 2011). The SWOT methodology especially is informed by the subjective views of participants. Additionally, SWOT methodology focusses on providing a complete overview of an analysed situation, as such the gathered factors are not ranked by significance but rather displayed and analysed as a whole (Phadermrod et al. 2019). This implies that the recommendations derived from the SWOT analysis cannot be weighted and are therefore presented as equally significant.

All stakeholders, though they were interviewed in their professional capacity as spokespeople for their respective sectors, are members of the wider society beyond their respective fields. As such, their responses contain societal viewpoints, differing based on their professional backgrounds. However, though they might raise viewpoints primarily relevant to civil society, their perceptions still have to be regarded as influenced by their background. The presented SWOT catalogue therefore cannot be free of bias and must be regarded as a snapshot of the most relevant factors identified by past research, given context by the perceptions of the selected key stakeholders. It represents a status quo of the discourse around this combination in Germany, based on the listed past research as well as the understanding and perceptions of the interviewed stakeholders. This status quo is highly dependent on this understanding and perception of the interviewees as well as the evolution of the public discourse over time.

However, combining the SWOT approach with semistructured qualitative expert interviews can yield new perspectives and avenues for a renewed public and academic discourse on the topic of multi-use. Especially the structured recommendations derived from this approach open up new avenues for exploration.

\section{Results and discussion}

Table 2 shows the complete SWOT factor catalogue for OWF and mariculture multi-use in the German North Sea EEZ based on results of identified relevant past research 
Table 2 Complete SWOT factor catalogue for OWF and mariculture multi-use in the German North Sea EEZ based on results of identified relevant past research projects (Table 1). Factors were discussed, validated and amended where necessary to reflect viewpoints and perceptions of four key stakeholders from OWF and mariculture industries, regulatory bodies and academia

Potential Restrictions

\section{Strengths}

Increased food production contributes to national food security, decreases reliance on seafood imports

Develops new export opportunities through the development of specialised MAQ technologies

Possible reconnection with cultural identities of coastal fisheries communities

Opens up space in Germany's North Sea EEZ to intensify and manage ocean uses where it previously was not possible

Growth of the blue economy will deliver economic development, especially in structurally weaker coastal communities and around harbours

Spatial efficiency in planning will allow planners to reserve ocean space for other emerging and future uses

\section{Weaknesses}

Growing environmental awareness and a lack in nuanced information about environmental impacts environmentally harmful mariculture combined with factory farming

Sharing of information on e.g. health and safety concepts requires close legal coordination

Licensing and impact assessments for multiple uses are to date conducted separately

Lack of accurate cost-benefit analysis for both users

Current legal framework does not sufficiently regulate rights and responsibilities in multi-use setting

Insurance schemes for multi-use operations have not yet been established

Investment into innovation is precarious due to uncertain policy backing

\section{Threats}

Intensification of industrial uses might lead to increased environmental footprint if not managed sustainably and assessed through the use of cumulative impact assessments

Industrialising the sea might lead to more traffic, busy harbours, horizontal pollution, as well as to various risks (e.g. accidents, oil spills)

Potential liability issues stifle willingness of involved actors

Interference of operations without coordination between actors

Lack of arbitration and conflict resolution frameworks of uses as well as the general fear of

Possible cost savings for both users through sharing of services, infrastructure and assessments

Joint marketing approaches ease obtaining of a societal license to operate

Cost saving through increased innovation potential projects (Table 1). Dissecting these factors of the common discourse reveals two distinct viewpoints within this discourse. Table 3 and Table 4 show the SWOT factors for the societal and industry-focussed analyses, respectively. These factors were derived from the relevant past research projects and verified and refined with the selected stakeholders during the interviews. Factors are displayed in the categories strengths, weaknesses, opportunities and threats as well as internal and external.

In the following subchapter, we place the factors into perspective of current developments and highlight key considerations which are inherent to the multi-use combination. A clear distinction has to be made between the inherent strengths of the combination of the two uses and the possible opportunities that joint operations and marketing schemes may hold.

\section{Societal focus}

\section{Strengths}

The benefits of the combination of OWFs and mariculture in Germany's EEZ for society as a whole can be ascribed to four major themes: food security (i.e. the availability of safe and nutritious foods to the population, especially in times of global shortages), economic growth, spatial efficiency and reduced environmental impact. An introduction of large-scale mariculture in the case study area holds the potential to satisfy parts of the domestic and European seafood demand and might partially displace international import. Recent shutdowns caused by the worldwide corona pandemic have shown the vulnerability in our globalised value chains and have prompted 
Table 3 SWOT analysis of combinations of offshore wind farms and mariculture installations with a focus on society centric factors.

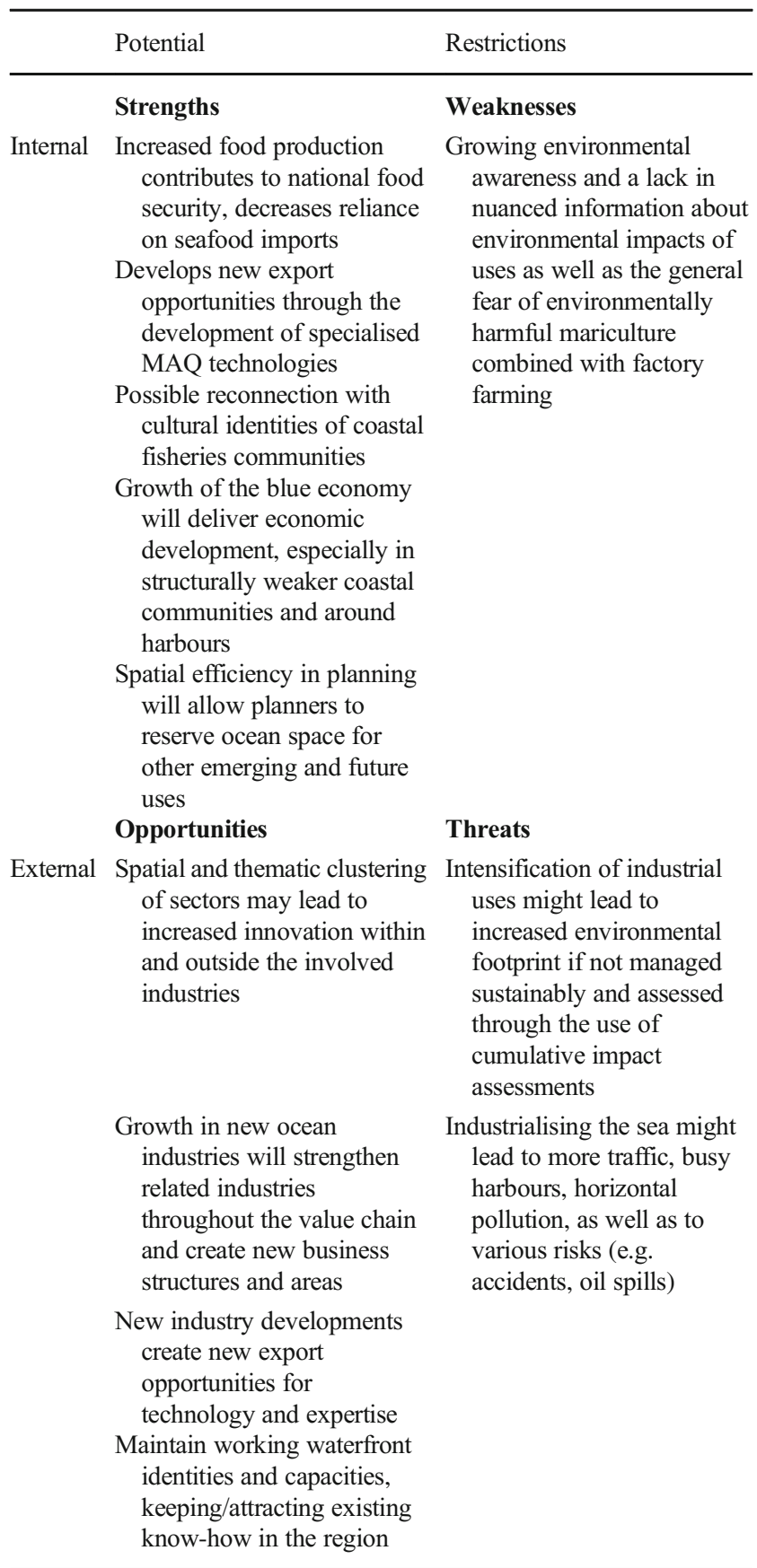

discussions on securing domestic production of essential goods, including food, for domestic markets (FAO 2020). A local production does not only decrease the part of its carbon footprint caused by the transport of the final product, but would also have to adhere to stringent environmental regulations resulting in a lower impact industry which poses a global net benefit if it results in less outsourcing of pollution into other parts of the world (Herrmann and Hauschild 2009). The introduction of a new sector like mariculture holds
Table 4 SWOT analysis of combinations of offshore wind farms and mariculture installations with a focus on industry-centric factors

\begin{tabular}{|c|c|c|}
\hline & Potential & Restrictions \\
\hline & Strengths & Weaknesses \\
\hline \multirow[t]{7}{*}{ Internal } & $\begin{array}{l}\text { Opens up space in Germany's } \\
\text { North Sea EEZ to intensify } \\
\text { and manage ocean uses } \\
\text { where it previously wasn't }\end{array}$ & $\begin{array}{l}\text { Sharing of information on e.g. } \\
\text { health and safety concepts } \\
\text { requires close legal } \\
\text { coordination }\end{array}$ \\
\hline & & $\begin{array}{l}\text { Licensing and impact } \\
\text { assessments for multiple } \\
\text { uses are to date conducted } \\
\text { separately }\end{array}$ \\
\hline & & $\begin{array}{l}\text { Lack of accurate cost-benefit } \\
\text { analysis for both users }\end{array}$ \\
\hline & & $\begin{array}{l}\text { Current legal framework does } \\
\text { not sufficiently regulate } \\
\text { rights and responsibilities in } \\
\text { multi-use setting }\end{array}$ \\
\hline & & $\begin{array}{l}\text { Insurance schemes for } \\
\text { multi-use operations have } \\
\text { not yet been established }\end{array}$ \\
\hline & & $\begin{array}{l}\text { Investment into innovation is } \\
\text { precarious due to uncertain } \\
\text { policy backing }\end{array}$ \\
\hline & Opportunities & Threats \\
\hline \multirow[t]{3}{*}{ External } & $\begin{array}{l}\text { Possible cost savings for both } \\
\text { users through sharing of } \\
\text { services, infrastructure and } \\
\text { assessments }\end{array}$ & $\begin{array}{l}\text { Potential liability issues stifle } \\
\text { willingness of involved } \\
\text { actors }\end{array}$ \\
\hline & $\begin{array}{l}\text { Joint marketing approaches } \\
\text { ease obtaining of a societal } \\
\text { license to operate }\end{array}$ & $\begin{array}{l}\text { Interference of operations } \\
\text { without coordination } \\
\text { between actors }\end{array}$ \\
\hline & $\begin{array}{l}\text { Cost saving through increased } \\
\text { innovation potential }\end{array}$ & $\begin{array}{l}\text { Lack of arbitration and } \\
\text { conflict resolution } \\
\text { frameworks }\end{array}$ \\
\hline
\end{tabular}

potential for economic growth and reshaping local identities of food production, especially in structurally weaker coastal communities which have often been eclipsed by the economic growth of the last decades. Maintaining and strengthening these 'working waterfronts' is one key socio-economic and cultural benefit of mariculture (Krause et al. 2020). Even with the high level of automation necessary to compete with foreign imports, there is a large potential of added value throughout the local seafood value chain, as well as in the provisioning industries (EUMOFA 2019). However, it is worth noting that mostly larger companies will have access to the required capital to finance and maintain large-scale offshore mariculture operations. Such companies are often far removed from the traditional working water fronts and disconnected from the cultural heritage of coastal fishing communities. The potential benefit of such offshore mariculture developments for these communities will therefore have to be further investigated.

Lastly, striving for a high degree of spatial integration between stationary uses allows spatial planners to potentially 
reserve areas for other uses. Such hard to zone uses are, amongst others, mobile fisheries, conservation efforts or perhaps other future uses such as carbon sequestration and others not yet accounted for in current marine spatial plans (MSP). The sparing use of marine space for the protection of the natural environment and the provision of future potential is one of the policy guidelines underlying Germany's MSP (BMVBS 2009; Douvere and Ehler 2010).

\section{Weaknesses}

The key weakness from a societal standpoint inherent to the combination of uses is related to stakeholder perceptions around the environmental impact of marine uses. Germany has a strong and institutionalised environmental movement that has its roots in the anti-war and anti-nuclear movements of the 1960s and 1970s (Rucht and Roose 1999; Brand 1999). This deeply embedded culture of environmental activism clashes with the oftentimes lacking variety in the information available to the general public about the possible environmental impacts of mariculture systems and their variety. Stories about negative impacts of unrestrained and unmanaged mariculture as well as OWF development oftentimes still dominate the news narrative and colour the public perception (Feucht and Zander 2017; Ladenburg and Krause 2011). It stands to reason that any mariculture development must satisfy the high standards and demands of not only the official regulations but also the high standards of the public.

\section{Opportunities}

The opportunities for society follow the main themes of innovation, strengthening of old and new industries and opportunities for growth (Krause and Stead 2017). The spatial and thematic, e.g. in maritime clusters, clustering of related industries has previously shown to potentially lead to an increase in cooperation and innovation (European Commission 2008). This catalysing effect of integration holds the potential to create new technologies, new industries and foster innovation in related industries up and down the value chain. These new technologies and solutions in turn offer export opportunity for know-how and technology to other countries (Stavroulakis and Papadimitriou 2015).

\section{Threats}

A local intensification of uses could potentially lead to an increased environmental footprint if compounding effects on the marine ecosystem are disregarded and the multiple uses are not managed effectively, using cumulative and integrated environmental impact assessments (Onyango et al. 2020). An intensification of maritime industries will also inevitably increase the maritime traffic around offshore and harbour installations, increasing the likelihood of accidents and potentially causing horizontal pollution across multiple uses. Such pollution can either be caused by the joining of the two activities (shared platforms) or simply by the increase in its local concentration by the close geographic clustering of uses (van Hoof et al. 2020). Society's perception of these cumulative threats can potentially threaten developments if they cross thresholds of societal concern (TSC) and no adequate avoidance and mitigation measures are implemented and communicated (Christensen and Krogman 2012). The concept of the TSC is based on thresholds of potential concern (TPC), which are being used in environmental management (Rogers et al. 2013), and are a product of both the public's risk perception and values. It is subject to change regardless of whether the actual risks have changed and might largely determine the granting or withdrawal of an SLO.

\section{Industry focus}

\section{Strengths}

The key strength for a multi-use scenario combining mariculture and OWFs stems from Germany's crowded coastal regions. The ability to conduct any mariculture operations in the German Bight can be severely hampered by the omnipresence of other users and uses competing for the scarce available space. Between expanding uses, like marine renewables, and existing uses with evolving spatial requirements, such as shipping and areas set aside for nature conservation, the suitable areas for mariculture are few and far between. A combination of the two sectors opens up potentially large areas in future OWFs and around existing parks to cultivation which would otherwise be inaccessible.

\section{Weaknesses}

One of the key weaknesses to the combination of OWFs and mariculture is the lack of long-term investment strategies by public and private financial institutions. This is mainly rooted in the lack of clear policy backing. This situation makes it hard for companies looking to expand offshore to find sufficient capital to bear the high upfront costs associated with offshore operations. Furthermore, the combination of two uses will require a varying degree of information flow between the involved users. This may start with a simple exchange of information on operations and requirements but may also develop into an integration of operations to achieve synergistic effects. This exchange of information and coordination poses a significant weakness as there is to date no legal framework to govern such relationships between actors. Without it, actors are unlikely to reveal sensitive operational details needed to achieve closer integration and unlock the cost sharing potential (Krause and Stead 2017). Similarly, to the information 
flow between actors, the communication between actors and regulators is often conducted separately. Joint licensing procedures and impact assessments offer a large potential for synergies. However, they are often conducted based on a sectoral approach which does not consider multi-use potential. This is, in part, because current legal frameworks do not sufficiently consider multi-use, or any potential mariculture use for that matter. It is not recognised as a clear option for spatial management and as such rights and responsibilities of different users in such a setting are not settled. There is also a lack of accurate cost-benefit assessments for all involved actors available and no bespoke insurance products exist yet for the mariculture sector, but especially for operations in multi-use settings.

\section{Opportunities}

One of the key potentials the combination of OWFs and mariculture holds for businesses is the potential to create a more positive societal perception of the combined activities by cooperating to obtain the support of more communities and stakeholder groups (Matti and Sandström 2013; Voyer and van Leeuwen 2019). Any maritime industry, and especially mariculture and marine renewables, such as offshore wind energy, has to fight an uphill battle in gaining an SLO. Some societal perceptions barring it are often focussed around environmental concerns such as fears of pollution, a lack of sustainability in business practices or visual pollution of coastal areas. A combination of the two sectors, if branded and marketed as sustainable, could therefore lead to a bettering of the image of the combined activities. The remaining strengths focus mostly on secondary effects interactions between the sectors or their value chains. Two integrated uses will have similar requirements in certain aspects of technology and will be able to indirectly benefit from the innovation and availability in knowledge and technology around offshore operations (European Commission 2008; Stavroulakis et al. 2015). Advances made in e.g. sensor systems and mooring technology will benefit associated sectors as they become available to the wider market.

\section{Threats}

A key potential threat to the combination of uses is the possibility of interference of operations due to the activities of one or more actors (van Hoof et al. 2020). This can take the form of mariculture harvesting activities hindering operations and maintenance activities on OWF infrastructure. The logical escalation of this threat is the possibility of one actor's actions directly or indirectly causing damage to the other actor's infrastructure. Such damages can have varying severity and require clear mechanisms for assigning liability between actors operating in the same area. One avoidance strategy is for specific secondary uses to be allowed within safety areas of OWFs. This could reduce the risk of user-user interference while also keeping mariculture installations clear of other ocean users (Gimpel et al. 2020). Regardless of the severity of the damage, there is currently no arbitration process in place to address arising problems and grievances between actors. However, recent research is starting to address the lack of risk analysis and mitigation schemes (van Hoof et al. 2020).

\section{Recommendations}

Dissecting the SWOT analysis allows for a strategic analysis of the current situation based on only the MU relevant factors. Furthermore, disregarding sector specific strengths and challenges focussed the discussion on the factors which make MU unique and uniquely challenging. At first glance, strengths and opportunities of the OWF and mariculture multi-use combination seem to outweigh weaknesses and threats from the societal standpoint while the industry-centric analysis seems to abound with weaknesses and threats. However, this apparent dichotomy can at least partially be explained by the mismatch of research efforts which have been devoted to the investigation of either side. Discussions of the multi-use of OWFs and mariculture have long since focussed on biological and technological practicability as well as economic feasibility and stakeholder perceptions (Buck and Langan 2017; Bocci et al. 2019).

Based on the key factors governing MU development in the case study area derived through the SWOT analysis, a set of recommendations have been derived from general MU development frameworks (Schultz-Zehden et al. 2018; Schupp and Buck 2017). These recommendations were then reviewed and revised by stakeholders after the interview stage. The recommendations are structured according to five proposed priority lines to support future development. They are as follows: site selection, pilot development, financing, modelling cooperation, legal frameworks and a cross-cutting theme of knowledge transfer. Table 5 shows the recommendations grouped according to these priority lines and designates the key stakeholder group essential for accomplishing each action. Though only one group is designated per recommendation, a continuous exchange and knowledge transfer between all actors throughout the process has shown to be paramount in developing relevant outcomes (Krause and Schupp 2019).

\section{Site selection}

Selecting and designating appropriate sites for OWF and mariculture multi-use poses a challenge to established MSP schemes as it needs to consider the needs of all involved sectors while still minimising conflict potential with other uses. Especially mariculture presents novel challenges in zoning 


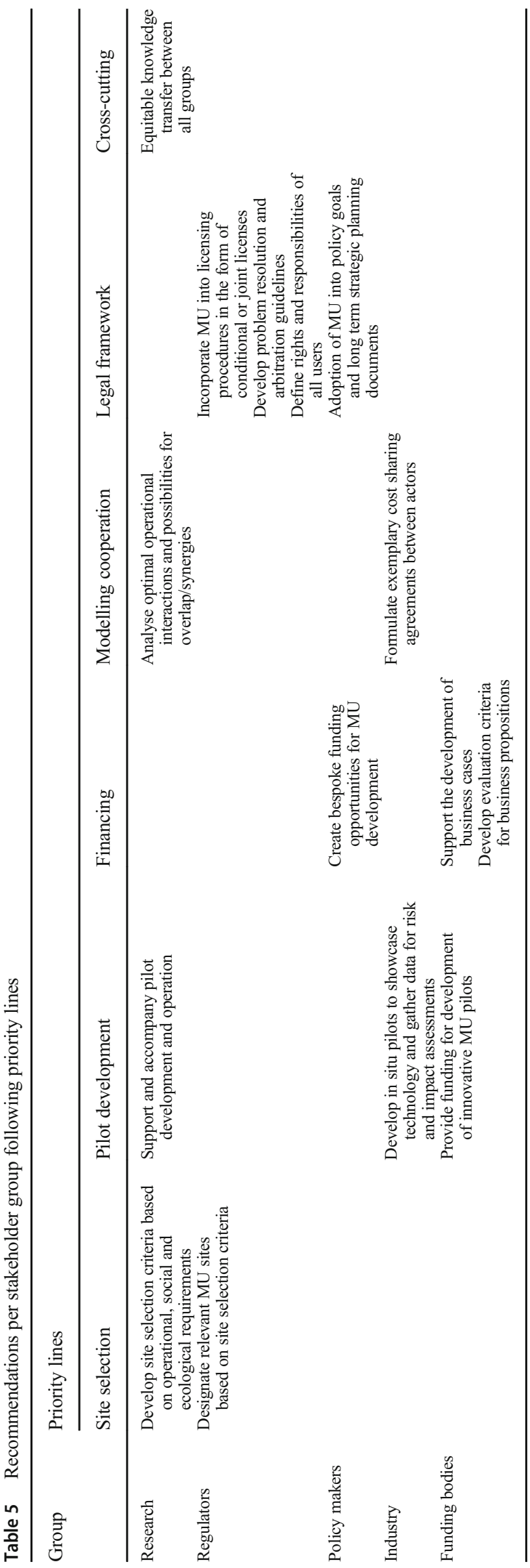

due to the high variability in biological and operational requirements. Depending on the culture organism and system employed, requirements can differ widely. Both researchers and regulators must collaborate in defining and applying appropriate operational, social and ecological site selection criteria. Based on these criteria, areas for the development of mariculture can be identified and, where these overlap with areas marked for OWF development, potentially be designated as suitable for MU development.

\section{Pilot development}

The research sector has to date developed multiple small-scale pilots and conducted in situ testing for the MU concept (Buck and Langan 2017). However, the development and operation of medium to full-scale pilot facilities cannot be achieved by fixed-term research projects but rather require companies to take the lead in development and financing. This should be conducted as a joint effort between research and industry in order to make use of all available knowledge and to bring innovations quickly to market. Such public-private partnerships taking on the required $R \& D$ spending should be supported by the relevant funding agencies in order to shorten the time to market and ease licensing.

\section{Financing}

As neither the research sector nor industry can bear the burden of the required investment on their own, MU requires the creation of bespoke funding instruments in order to boost private investment and innovation in the sector. Policy makers have previously and to great effect taken such supportive actions which enabled the creation of OWF in German waters by providing prospective developers with support until new concepts are sufficiently mature (Offshore Wind Energy Act 2017). Such support can either take the form of government grants to developer's conditional on certain investment thresholds being met, acting as guarantor for required loans or subsidies similar to agricultural subsidies. Funding bodies should additionally specifically fund the creation of business cases to promote MU investment to private investors. Some such business cases have been investigated by Buck et al. (2010), Jansen et al. (2016) and van den Burg et al. (2017). At the same time, evaluation criteria for such business cases in a multi-use setting, specifically regarding risk assessments, need to be further developed.

\section{Modelling cooperation}

Minimising the conflict potential between the two users while maximising the potential for synergistic effects requires a detailed operational analysis of the entire MU over its lifecycle (Michler-Cieluch 2010; Michler-Cieluch et al. 2009b). Such 
assessments can be undertaken by the research sectors in collaboration with industry representatives in order to create detailed operational models based on state-of-the-art process knowledge. Identifying overlaps in such operational models helps in addressing conflicts before they appear while also opening a dialogue about possibilities for cost-sharing. Industry representatives need to then take the lead on formulating exemplary cost-sharing agreements between actors, which can serve to minimise investments and operating costs for both sides.

\section{Legal framework}

MU needs to be mainstreamed in the legal and regulatory national frameworks governing the use of the sea. It currently does not feature in key policy documents and is only mentioned as an option in the relevant MSP documents (BMVBS 2009). An adoption of MU as a preferred mode of usage, where possible, requires its adoption as a policy goal and inclusion in long-term strategic planning documents. The consideration of MU also needs to be incorporated into the licensing process for other uses like proposed in Buck et al. (2017). Licensing can be made conditional on using a multi-use approach where possible or preferred licensing can be given to innovative MU approaches. One positive example of the application of such licensing practices spurring technology development can be found in Norway's development licensing scheme for mariculture. Sought-after licenses are provided at a reduced rate and on a conditional basis to users investing in innovative solutions to offshore mariculture (Aarset and Jakobsen 2009; Greaker et al. 2020). This system has resulted in e.g. the development of the Ocean Farm-1 prototype currently in use by SalMar ASA and similar systems in China. These prototypes are pushing the boundaries of what were previously thought possible. In light of these developments, current and prospective users require clarification of all rights and responsibilities of other users acting within the same area. Regulators need to develop and put in place pathways for problem resolution and arbitration between users in anticipation of future disputes and conflicts as well as to alleviate concerns hindering investment in offshore innovations.

\section{Cross-cutting theme: knowledge transfer}

The development of functional MU scenarios needs to be based on the concepts of using best available technology (BAT) and best management practice (BMP) as well as the best environmental practices (BEP) (Read and Fernandes 2003; FAO 2011). Towards this end, multi-directional knowledge transfer between all involved parties has to be achieved in order to make use of the best available knowledge. Past research projects have already addressed many potential challenges either partially or fully and can help in further development if the knowledge can be shared and applied. Additionally, the practical knowledge held by practitioners in the relevant sectors as well as regulators is indispensable in creating market-ready real-life applications with good chances of success. A trans-disciplinary co-design approach can serve to achieve such solutions (Hörterer et al. 2018).

\section{Concluding remarks}

Dissecting the SWOT analysis of multi-use of OWFs with mariculture highlights that there are several hidden knowledge gaps and opportunities, which need to be tackled before marine food and energy production can be transformed. The multi-use is based on several inherent strengths but offers even more opportunities for both society as well as industry. Past and present research efforts as well as stakeholders' dialogues have however revealed many weaknesses and potential threats related to the combination of sectors. These barriers to multiuse development need to be addressed while the possible benefits of the combination are further researched and communicated. Looking beyond the scope of these multi-use specific factors analysed in this paper, there is a layer of sector specific challenges to overcome, which can be as or more important in achieving multi-use scenarios. Society's perception of maritime industry is a key factor influencing any future development. As such, the interrelationship between societal values and industry development needs to be further researched in order to create socially sustainable outcomes.

The outlined recommendations represent a holistic research agenda addressing the key barriers and building on benefits in order to realise a MU development. However, while this analysis is based on Germany's specific situation with a crowded seascape, the recommendations, as well as the methodology employed, might prove to be transferrable to MU developments currently ongoing in other countries. Likewise, the continued multi-use development in Germany is dependent on a continuous exchange between national and international actors on all levels to facilitate learning from international best practice scenarios.

The close integration of multiple ocean use sectors is one pathway towards boosting sustainable innovation in the blue economy. Emerging growth sectors, such as mariculture, may benefit from a stepping-stone effect in their move further and further offshore through the exploitation of spatial and operational synergies, while more established sectors such as offshore renewables may reduce their operating costs and maintain their SLO. As these uses move further and further offshore, further away from countries' territorial waters, existing legal and planning frameworks will begin to come under pressure trying to keep up with technological development. While existing and developing national MSP procedures hold a potential to governing these uses within territorial waters and 
EEZs, the scope of future investigation needs to turn even further offshore in order to pre-empt future challenges.

This study and the factors presented using the bi-focal SWOT analysis, as well as the derived recommendations, should serve not as a starting or end point, but rather as a check point for the public and academic discourse on OWF and mariculture multi-use in Germany. It expands on the previous body of research in the study area while complementing previous results with the help of key stakeholders in the involved industries, regulatory bodies and academia. The status quo of the discourse presented here is expected to change and adapt as the topic is picked up and prioritized by new societal groups and, likewise, the SWOT factor catalogue for society and industry, as well as the derived recommendations, needs to adapt and change as the topic progresses.

Supplementary Information The online version contains supplementary material available at https://doi.org/10.1007/s40152-021-00218-1.

Acknowledgements This work is partly based on the research and knowledge of the expert group assembled in the MUSES project (EU Horizon 2020 Grant agreement no 727451) and would not have been possible without the invaluable expertise shared with its members by the countless stakeholders who participated in interviews or workshops in order to further the multi-use concept.

Author contribution MS is lead author, conceived and designed the study, wrote and reviewed the manuscript and prepared the manuscript for submission. GK, $\mathrm{VO}$ and $\mathrm{BHB}$ provided critical input to study design and reviewed the manuscript in all stages.

Funding Open Access funding enabled and organized by Projekt DEAL. This project has received funding from the European Union's Horizon 2020 Research and Innovation Programme under grant agreement no. 727451.

Data availability The datasets generated for this study are available upon request to the corresponding author.

\section{Declarations}

Ethics approval This project was exempted from ethics approval in accordance with the regulations of the German Research Foundation (DFG) and the Council for Social and Economic Data (RatSWD), as all collected information were anonymous and non-sensitive and participants are not identifiable. Participants were explicitly informed about and consented to the aim of the study, the methodology and about what data will be collected, processed, stored and published. All data were collected, stored and processes in compliance with the General Data Protection Regulation (GDPR).

Conflict of interest The authors declare no competing interests.

Open Access This article is licensed under a Creative Commons Attribution 4.0 International License, which permits use, sharing, adaptation, distribution and reproduction in any medium or format, as long as you give appropriate credit to the original author(s) and the source, provide a link to the Creative Commons licence, and indicate if changes were made. The images or other third party material in this article are included in the article's Creative Commons licence, unless indicated otherwise in a credit line to the material. If material is not included in the article's Creative Commons licence and your intended use is not permitted by statutory regulation or exceeds the permitted use, you will need to obtain permission directly from the copyright holder. To view a copy of this licence, visit http://creativecommons.org/licenses/by/4.0/.

\section{References}

Aarset, Bernt, and Stig-Erik Jakobsen. 2009. Political regulation and radical institutional change: The case of aquaculture in Norway. Marine Policy 33 (2): 280-287. https://doi.org/10.1016/j.marpol.2008.07.006.

Biernacki, Patrick, and Dan Waldorf. 1981. Snowball sampling: Problems and techniques of chain referral sampling. Sociological Methods \& Research 10 (2): 141-163. https://doi.org/10.1177/ 004912418101000205.

BMVBS. 2009. Anlage zur Verordnung über die Raumordnung in der deutschen ausschließlichen Wirtschaftszone in der Nordsee (AWZ Nordsee-ROV) vom 21. September 2009. In Bau und Stadtentwicklung Der Bundesminister für Verkehr, ed. G 5702. Berlin: Bundesanzeiger.

BMZ. 2017. Der Zukunftsvertrag für die Welt - Die Agenda 2030 für nachhaltige Entwicklung. Germany: Bonn.

Bocci, M., S.J. Sangiuliano, A. Sarretta, J.O. Ansong, B. Buchanan, A. Kafas, M. Cana-Varona, et al. 2019. Multi-use of the sea: A wide array of opportunities from site-specific cases across Europe. PLoS One 14 (4): e0215010. https://doi.org/10.1371/journal.pone. 0215010 .

Brand, Karl-Werner. 1999. Dialectics of institutionalisation: The transformation of the environmental movement in Germany. Environmental Politics 8 (1): 35-58. https://doi.org/10.1080/ 09644019908414437.

Buck, Bela Hieronymus. 2007. Experimental trials on the feasibility of offshore seed production of the mussel Mytilus edulis in the German Bight: Installation, technical requirements and environmental conditions. Helgoland Marine Research 61 (2): 87-101. https://doi.org/ 10.1007/s10152-006-0056-1.

Buck, Bela H., and Richard Langan. 2017. In Aquaculture Perspective of Multi-Use Sites in the Open Ocean, ed. B.H. Buck and R. Langan. Cham: Springer International Publishing AG.

Buck, B. H., G. Krause, T. Michler-Cieluch, M. Brenner, C. M. Buchholz, J. A. Busch, R. Fisch, M. Geisen, and O. Zielinski. 2008. Meeting the quest for spatial efficiency: progress and prospects of extensive aquaculture within offshore wind farms. Helgoland Marine Research 62(3): 269-281. https://doi.org/10. 1007/s10152-008-0115-x.

Buck, B.H., U. Walter, G. Liebezeit, S. Spahic, I. Walter, and Victor Smetacek. 2004. Aquakultur in der Nordsee: Untersuchungen zum Ansiedlungs- und Wachstumspotential von Muscheln und Makroalgen in der Deutschen Bucht zur Überprüfung der Eignung von Offshore-Standorten für Marine Aquakultur. In Förderung durch den Senat für Umwelt und Verkehr, Bremen. Endbericht des Projektes FV 142. Bremerhaven, Wilhelmshaven.

Buck, B.H., O. Zielinski, A. Assheuer, K. Wiemann, C. Hamm, and D. Kassen. 2006. AquaLast - Technische Umsetzung von extensiven Marikulturanlagen in Windparks: Betrachtung der mechanischen Lasten, Endbericht des Projektes FV 174, gefördert durch den SBUV des Landes Bremen. Bremerhaven.

Buck, B.H., A. Köhler, M. Brenner, M. Stede, and M. Engel. 2007. MytiFit: Eignung des Seegebietes am geplanten OffshoreWindpark "Nordergründe" für die Zucht von Miesmuscheln: Fitness, Parasitisierung und Substratwahl. Förderprogramm Angewandte Umweltforschung (AUF), Senator für Umwelt, Bau, 
Verkehr und Europa, Bremen. In Endbericht des Projektes FV 168. Bremerhaven.

Buck, Bela H., Michael W. Ebeling, and Tanja Michler-Cieluch. 2010. Mussel cultivation as a co-use in offshore wind farms: Potential and economic feasibility. Aquaculture Economics \& Management 14 (4): 255-281. https://doi.org/10.1080/13657305.2010.526018.

Buck, B.H., J. HDubois, M.W. Ebeling, Benjamin Franz, Nils Goseberg, Matthias Hundt, Peter Schaumann, et al. 2012. Mulitple Nutzung und Co-Management von Offshore-Strukturen: Marine Aquakultur und Offshore-Windparks. In Open Ocean Multi-Use (OOMU)Projektbericht, gefördert durch das Bundesministerium für Umwelt, Natur-schutz und Reaktorsicherheit. Bremerhaven.

Buck, Bela H., Gesche Krause, Bernadette Pogoda, Britta Grote, Lara Wever, Nils Goseberg, Maximilian F. Schupp, Arkadiusz Mochtak, and Detlef Czybulka. 2017. The German case study: pioneer projects of aquaculture-wind farm multi-uses. In Aquaculture Perspective of Multi-Use Sites in the Open Ocean, ed. B.H. Buck and R. Langan, 253-354. Cham: Springer International Publishing AG.

Christensen, Lisa, and Naomi Krogman. 2012. Social thresholds and their translation into social-ecological management practices. Ecology and Society 17 (1). https://doi.org/10.5751/es-04499-170105.

Douvere, Fanny, and Charles N. Ehler. 2010. The importance of monitoring and evaluation in adaptive maritime spatial planning. Journal of Coastal Conservation 15 (2): 305-311. https://doi.org/10.1007/ s11852-010-0100-9.

Dyson, R.G. 2004. Strategic development and SWOT analysis at the University of Warwick. European Journal of Operational Research 152 (3): 631-640. https://doi.org/10.1016/S03772217(03)00062-6.

EUMOFA. 2019. Case Study: Fresh Mussels in the EU, Price strucutre in the supply chain. Luxembourg: European Market Observatory for Fisheries and Aquaculture (EUMOFA).

European Commission. 2008. The role of maritime clusters to enhance the strength and development of European maritime sectors. Brussels: European Commission.

FAO. 2011. Code of Conduct for Responsible Fisheries. Rome: Food and Agriculture Organisation of the United Nations.

FAO. 2020. Addressing the impacts of COVID-19 in food crises - AprilDecember 2020 FAO's component of the Global COVID-19 Humanitarian Response Plan. Rome, Italy: FAO Emergency and Resilience Division.

Fertel, Camille, Olivier Bahn, Kathleen Vaillancourt, and Jean-Philippe Waaub. 2013. Canadian energy and climate policies: A SWOT analysis in search of federal/provincial coherence. Energy Policy 63: 1139-1150. https://doi.org/10.1016/j.enpol.2013.09.057.

Feucht, Yvonne, and Katrin Zander. 2017. Aquaculture in the German print media. Aquaculture International 25 (1): 177-195. https://doi. org/10.1007/s10499-016-0021-1.

Gimpel, Antje, Vanessa Stelzenmüller, Maximilian Felix Schupp, Bela H. Buck, Holger Huhn, and Andrea Falldorf. 2020. Abschlussbericht "Offshore-Windparks im Kontext ökosystembasierter Raumplanung und Nutzung”. Bremerhaven: Thünen Institut for Sea Fisheries.

Goffetti, Giulia, Massimiliano Montini, Francesca Volpe, Massimo Gigliotti, Federico M. Pulselli, Gianmaria Sannino, and Nadia Marchettini. 2018. Disaggregating the SWOT Analysis of Marine Renewable Energies. Frontiers in Energy Research 6. https://doi. org/10.3389/fenrg.2018.00138.

Greaker, Mads, Irja Vormedal, and Kristin Rosendal. 2020. Environmental policy and innovation in Norwegian fish farming: Resolving the sea lice problem? Marine Policy 117: 103942. https://doi.org/10.1016/j.marpol.2020.103942.

Helfferich, Cornelia. 2011. Die Qualität qualitativer Daten - Manual für die Durchführung qualitativer Interviews. 4th ed. Aufl.: VS Verlag.
Herrmann, I.T., and M.Z. Hauschild. 2009. Effects of globalisation on carbon footprints of products. CIRP Annals 58 (1): 13-16. https:// doi.org/10.1016/j.cirp.2009.03.078.

Hörterer, Christina, Maximilian Schupp, Andreas Benkens, and Bela H. Buck. 2018. Climate change and biodiversity_implications for the local fisheries sector. In In Building Bridges at the ScienceStakeholder Interface, 31-38. SpringerBriefs in: Earth System Sciences.

ICSU. 2017. A Guide to SDG Interaction: From Science to Implementation. Paris: International Council for Science (ICSU).

Jansen, H.M., S. Van Den Burg, B. Bolman, R.G. Jak, P. Kamermans, M. Poelman, and M. Stuiver. 2016. The feasibility of offshore aquaculture and its potential for multi-use in the North Sea. Aquaculture International 24 (3): 735-756. https://doi.org/10.1007/s10499-0169987-y.

Krause G, Schupp MF 2019. Evaluating knowledge transfer at the interface between science and society. GAIA - Ecological Perspectives for Science and Society 28 (3): 284-293. https://doi.org/10.14512/ gaia.28.3.9.

Krause, Gesche, and Selina M. Stead. 2017. Governance and offshore aquaculture in multi-resource use settings. In Aquaculture Perspective of Multi-Use Sites in the Open Ocean, ed. B.H. Buck and R. Langan, 149-162. Cham, Switzerland: Springer.

Krause, Gesche, Suzannah-Lynn Billing, John Dennis, Jon Grant, Lucia Fanning, Ramón Filgueira, Molly Miller, José Antonio Pérez Agúndez, Nardine Stybel, Selina M. Stead, and Wojciech Wawrzynski. 2020. Visualizing the social in aquaculture: How social dimension components illustrate the effects of aquaculture across geographic scales. Marine Policy 118: 103985. https://doi. org/10.1016/j.marpol.2020.103985.

Ladenburg, J., and G. Krause. 2011. Local attitudes towards wind power: The effect of prior experience. In From TUrbine to Wind Farms: Technical Requirements and Spin-Off Products, ed. G. Krause, 203218. InTECH.

Matti, Simon, and Annica Sandström. 2013. The defining elements of advocacy coalitions: Continuing the search for explanations for coordination and coalition structures. Review of Policy Research 30 (2): 240-257. https://doi.org/10.1111/ropr.12011.

Michler, T., B.H. Buck, and V. Smetacek. 2007. Marikultur in OffshoreWindparks. Abschlussbericht Teilprojekt 3.3 des BMBFVerbundprojektes Zukunft Küste - Coastal Futures. Bremerhaven.

Michler-Cieluch, T. 2010. Offshore Co-Management: Ein antizipierendes Modell für eine räumliche Integration von Offshore-Windparks und mariner Aquakultur. In Forschung für ein Integriertes Küstenzonenmanagement: Fallbeispiele Odermündungsregion und Offshore-Windkraft in der Nordsee, ed. Kannen, Schernewski, Krämer, Lange, Janßen, and Stybel, 59-70. Coastline Reports.

Michler-Cieluch, T., and S. Kodeih. 2008. Mussel and seaweed cultivation in offshore wind farms: An opinion survey. Coastal Management 36 (4): 392-411. https://doi.org/10.1080/ 08920750802273185 .

Michler-Cieluch, Tanja, and Gesche Krause. 2008. Perceived concerns and possible management strategies for governing 'wind farmmariculture integration'. Marine Policy 32 (6): 1013-1022. https:// doi.org/10.1016/j.marpol.2008.02.008.

Michler-Cieluch, T., G. Krause, and B.H. Buck. 2009a. Marine aquaculture within offshore wind farms: Social aspects of multiple-use planning. Gaia-Ecological Perspectives for Science and Society 18 (2): 158-162. https://doi.org/10.14512/gaia.18.2.14.

Michler-Cieluch, T., G. Krause, and B.H. Buck. 2009b. Reflections on integrating operation and maintenance activities of offshore wind farms and mariculture. Ocean \& Coastal Management 52 (1): 57 68. https://doi.org/10.1016/j.ocecoaman.2008.09.008.

Offshore Wind Energy Act. 2017. Gesetz zur Entwicklung und Förderung der Windenergie auf See (Windenergie-auf-See-Gesetz. - WindSeeG), ed. BMWI. 
Onyango, Vincent, Eva Papaioannou, Maximilian F. Schupp, Jacek Zaucha, Joanna Przedzymirska, Ivana Lukic, Mario Caña Varona, Angela Schultz-Zehden, Ioannis Giannelos, Rianne Läkamp, and Ilse van de Velde. 2020. Is demonstrating the concept of multi-use too soon for the North Sea? Barriers and opportunities from a stakeholder perspective. Coastal Management 48: 1-19. https://doi.org/ 10.1080/08920753.2020.1728206.

Phadermrod, B., R.M. Crowder, and G.B. Wills. 2019. Importanceperformance analysis based SWOT analysis. International Journal of Information Management 44: 194-203. https://doi.org/10.1016/j. ijinfomgt.2016.03.009.

Pogoda, Bernadette, Britta Grote, and Bela H. Buck. 2016. Project Report: "Offshore-Site-Selection für die nachhaltige und multifunktionale Nutzung von Meeresarealen in stark genutzten Meeren am Beispiel der Nordsee”. Bremerhaven, Germany: Alfred Wegener Institute, Helmholtz Centre for Polar and Marine Research.

Rasmussen, Lauge Baungaard. 2008. The narrative aspect of scenario building - how story telling may give people a memory of the future. In Cognition, Communication and Interaction: Transdisciplinary Perspectives on Interactive Technology, ed. Satinder Gill, 174194. London: Springer London.

Read, Paul, and Teresa Fernandes. 2003. Management of environmental impacts of marine aquaculture in Europe. Aquaculture 226 (1-4): 139-163. https://doi.org/10.1016/s0044-8486(03)00474-5.

Rogers, K., N. Saintilan, M.J. Colloff, and L. Wen. 2013. Application of thresholds of potential concern and limits of acceptable change in the condition assessment of a significant wetland. Environmental Monitoring Assessment 185 (10): 8583-8600. https://doi.org/10. 1007/s10661-013-3197-0.

Rucht, Dieter, and Jochen Roose. 1999. The German environmental movement at a crossroads? Environmental Politics 8 (1): 59-80. https://doi.org/10.1080/09644019908414438.

Sangiuliano, Stephen J., Susanne Altvater, Rebecca Bamlett, Andrea Barbanti, Martina Bocci, Bela H. Buck, Helena Calado, et al. 2018. MUSES Final Project Report \& Recommendations. Edinburgh, Scotland: Marine Scotland.

Schultz-Zehden, Angela, Ivana Lukic, Joseph Onwona Ansong, Susanne Altvater, Rebecca Bamlett, Andrea Barbanti, Martina Bocci, et al. 2018. Ocean Multi-Use Action Plan. Edinburgh: MUSES Project.

Schupp, M.F., and B.H. Buck. 2017. Case study 1C: Multi-use of offshore windfarms with marine aquaculture and fisheries (German North Sea EEZ - North Sea). Edinburgh: MUSES Project.

Schupp, M.F., M. Bocci, D. Depellegrin, A. Kafas, Z. Kyriazi, I. Lukic, A. Schultz-Zehden, G. Krause, V. Onyango, and B.H. Buck. 2019. Toward a common understanding of ocean multi-use. Frontiers in Marine Science 6. doi: UNSP 165. https://doi.org/10.3389/fmars. 2019.00165.

Smyth, K., N. Christie, D. Burdon, J.P. Atkins, R. Barnes, and M. Elliott. 2015. Renewables-to-reefs? - Decommissioning options for the offshore wind power industry. Marine Pollution Bulletin 90 (1-2): 247-258. https://doi.org/10.1016/j.marpolbul.2014.10.045.
Stavroulakis, Peter J. , and Stratos Papadimitriou. 2015. A hybrid SWOT analysis methodology for maritime clusters. Paper presented at the IAME 2015 Conference, Kuala Lumpur, Malaysia

Stavroulakis, Peter J., Stratos Papadimitriou, and Yannis Koliousis. 2015. The competitive advantage of maritime clusters. Paper presented at the IAME 2015 Conference, Kuala Lumpur, Malaysia, 2015.

Stelzenmüller, Vanessa, A. Gimpel, M. Gopnik, and K. Gee. 2017. Aquaculture site-selection and marine spatial planning: The roles of GIS-based tools and models. In Aquaculture Perspective of Multi-Use Sites in the Open Ocean, ed. Bela H. Buck and Richard Langan, 131-148. Cham: Springer International Publishing.

Tansey, Oisín. 2009. Process tracing and elite interviewing: A case for non-probability sampling. In Methoden der vergleichenden Politikund Sozialwissenschaft - Neue Entwicklungen und Anwendungen, ed. Susanne Pickel, Gert Pickel, Hans-Joachim Lauth, and Detlef Jahn, 481-496. Wiesbaden, Germany: VS Verlag für Sozialwissenschaften.

UN. 2015. Transforming Our World: The 2030 Agenda For Sustainable Development, ed. United Nations.

van den Burg, S.W.K., P. Kamermans, M. Blanch, D. Pletsas, M. Poelman, K. Soma, and G. Dalton. 2017. Business case for mussel aquaculture in offshore wind farms in the North Sea. Marine Policy 85: 1-7. https://doi.org/10.1016/j.marpol.2017.08.007.

van den Burg, S.W.K., José Aguilar-Manjarrez, Jeff Jenness, and Melanie Torrie. 2019. Assessment of the geographical potential for co-use of marine space, based on operational boundaries for Blue Growth sectors. Marine Policy 100: 43-57. https://doi.org/10.1016/j. marpol.2018.10.050.

van den Burg, S.W.K., Maximilian Felix Schupp, Daniel Depellegrin, Andrea Barbanti, and Sandy Kerr. 2020. Development of multiuse platforms at sea: Barriers to realising Blue Growth. Ocean Engineering 217: 107983. https://doi.org/10.1016/j.oceaneng. 2020.107983.

van Hoof, L., S.W.K. van den Burg, J.L. Banach, C. Röckmann, and M. Goossen. 2020. Can multi-use of the sea be safe? A framework for risk assessment of multi-use at sea. Ocean \& Coastal Management 184: 105030. https://doi.org/10.1016/j.ocecoaman.2019.105030.

Voyer, Michelle, and Judith van Leeuwen. 2019. 'Social license to operate' in the Blue Economy. Resources Policy 62: 102-113. https:// doi.org/10.1016/j.resourpol.2019.02.020.

Weiß, M., and B.H. Buck. 2017. Partial replacement of fishmeal in diets for turbot (Scophthalmus maximus, Linnaeus, 1758) culture using blue mussel (Mytilus edulis, Linneus, 1758) meat. Journal of Applied Ichthyology 33 (3): 354-360. https://doi.org/10.1111/jai. 13323.

Wever, Lara, Gesche Krause, and Bela H. Buck. 2015. Lessons from stakeholder dialogues on marine aquaculture in offshore wind farms: Perceived potentials, constraints and research gaps. Marine Policy 51: 251-259. https://doi.org/10.1016/j.marpol.2014.08.015.

Publisher's note Springer Nature remains neutral with regard to jurisdictional claims in published maps and institutional affiliations. 